\title{
Prediction of Long-Term Health Risk from Radiocesium Deposited on Ground with Consideration of Land-Surface Properties
}

\author{
Hiroshi Yasuda 10
}

check for updates

Citation: Yasuda, H. Prediction of Long-Term Health Risk from Radiocesium Deposited on Ground with Consideration of Land-Surface Properties. Appl. Sci. 2021, 11, 4424. https://doi.org/10.3390/app11104424

Academic Editors: Amit Kumar and Marina Cabral Pinto

Received: 4 April 2021

Accepted: 11 May 2021

Published: 13 May 2021

Publisher's Note: MDPI stays neutra with regard to jurisdictional claims in published maps and institutional affiliations.

Copyright: (C) 2021 by the author. Licensee MDPI, Basel, Switzerland. This article is an open access article distributed under the terms and conditions of the Creative Commons Attribution (CC BY) license (https:// creativecommons.org/licenses/by/ $4.0 /)$.
Research Institute for Radiation Biology and Medicine, Hiroshima University, 1 Kasumi 2-3, Minami-ku, Hiroshima 734-8553, Japan; hyasuda@hiroshima-u.ac.jp

Featured Application: More appropriate decision making on how to manage a land contaminated by hazardous materials would be possible by application of the site-specific approach for health risk assessment presented herewith.

Abstract: After the Fukushima Daiichi accident, there have been long controversial discussions on "how safe is safe?" between the authorities and the residents in the affected area. This controversy was partly attributable to the way the authorities made a judgement based on the annual effective dose rate; meanwhile, many of the local residents have serious concerns about future consequences for their health caused by chronic radiation exposure, particularly of small children. To settle this controversy, the author presents an approach based on long-term cancer risk projections of female infants, i.e., the most radiosensitive group, following land contamination by radiocesium deposition into ground with different surface conditions; the land was classified into three categories on the basis of decaying patterns of radiation dose rate: "Fast", "Middle", and "Slow". From the results of analyses with an initial dose rate of $20 \mathrm{mGy}$ per year, it was predicted that the integrated lifetime attributable risk (LAR) of cancer mortality of a female person ranged by a factor of 2 from $1.8 \%$ (for the Fast area) to $3.6 \%$ (for the Slow area) that were clearly higher than the nominal risk values derived from effective dose estimates with median values of environmental model parameters. These findings suggest that accurate site-specific information on the behavioral characteristics of radionuclides in the terrestrial environment are critically important for adequate decision making for protecting people when there is an event accompanied by large-scale radioactive contamination.

Keywords: terrestrial environment; radiocesium; cesium-137; radioactive contamination; cancer risk; radionuclide; nuclear accident; nominal risk; decision making

\section{Introduction}

After the severe nuclear accident that occurred at the Fukushima Daiichi nuclear power station on 11 March 2011, more than 160,000 people from within a $20 \mathrm{~km}$ zone and the area having relatively high radiation levels were forced to evacuate and, as of March 2021, more than 40,000 people are still recognized as evacuees [1]. While it is certain that those evacuation measures prevented some excessive radiation exposure of residents [2-4], it has caused severe psychological distress in evacuees who were forced to stay outside their home towns/villages for years [5,6].

Currently, most of the evacuation orders have been lifted in the affected areas where the levels of radioactive contamination are quite low. However, it seems many residents have not returned to their previous homes partly due to persistent concerns about the possible adverse health effects of chronic radiation exposure, despite the fact authorities have tried to convince them that they are overly concerned about the radiological effects by introducing the recommendations of international authorities such as the International Commission on Radiological Protection (ICRP). This standstill is attributable to the way 
authorities have provided explanations by the using short-term effective dose estimates. For example, soon after the accident occurred, the national and local governments announced that the reference level for such an emergency situation was typically in the effective dose band of 20 to $100 \mathrm{mSv}$, with citation of the basic recommendations of ICRP [7]. Though updates of these reference levels have been recommended by ICRP in a recent publication [8] as shown in Table 1, the decision process based on effective dose of a certain-scale population has not essentially changed.

Table 1. Updated reference levels for guiding the optimization of protection of members of the public during the successive phases of a nuclear accident [8].

\begin{tabular}{cc}
\hline Early and Intermediate Phase & Long-Term Phase \\
\hline $\begin{array}{c}100 \mathrm{mSv} \text { or below for the entire duration of } \\
\text { both the early and intermediate phases }\end{array}$ & $\begin{array}{c}\text { Lower half of the } 1 \text { to } 20 \mathrm{mSv} \text { per year band } \\
\text { with the objective to progressively reduce } \\
\text { exposure to levels towards the lower end of the } \\
\text { band or below, if possible }\end{array}$ \\
\hline
\end{tabular}

${ }^{1}$ Previously, the Commission recommended the selection of reference levels in the band of 20-100 $\mathrm{mSv}$ for emergency exposure situations. The current recommendation recognizes that in some circumstances, the most appropriate reference level may be below $20 \mathrm{mSv}$.

With their own experience of risk communication with the people affected by the nuclear accident in Fukushima, the author feels that many of the residents have been suspicious of such uniformly applied, dose-based approach since they know well that every individual could have a unique consequence on his/her health from the same dose radiation and, in particular, one with a higher radiosensitivity, like a small child, could suffer from more severe damage. Actually, it has been clearly shown by many experts that the radiosensitivity of humans significantly changes depending on age and sex. In general, smaller children are more radiosensitive than adults, which is attributable to the fact that children have more actively dividing cells that could amplify radiation-induced DNA damage to a large extent compared to the adults [9-13]. It is also known that female people are more radiosensitive in regard to carcinogenesis, mainly because the breast is notably susceptible to radiation compared to other organs $[7,9,11,13]$. Thus, it is desirable to answer more sincerely to their underlying question, "how safe is safe?", by precisely showing the health risk for the most sensitive group on a community basis, instead of just presenting an average value of effective dose for an anonymous general population. It is also desirable to show the integrated risk of all hazards, including possible effects of other toxic materials such as heavy metals and some organic compounds released into the environment, and then to enable the authorities to make more appropriate decisions through comprehensive optimization of those different-quality risks and benefits.

With these considerations, the author tries to present an approach for predicting long-term radiological risk of female infants, i.e., the most radiosensitive group, under the assumption that they would live on the land contaminated by radiocesium $\left({ }^{137} \mathrm{Cs}\right)$ with consideration of the difference in land-surface properties. The radiological impact of ${ }^{137} \mathrm{Cs}$, one of the most common products generated by the nuclear fission reaction, has been a subject of high concern in both Chernobyl and Fukushima Daiichi accidents because of its long half-life of about 30 years, chemically reactive feature, and high-energy $(0.662 \mathrm{MeV})$ $\gamma$-ray emissions [14-16]. Meanwhile, other long-lived radionuclides such as ${ }^{90} \mathrm{Sr}$ (half-life: 29 years) and ${ }^{106} \mathrm{Ru}$ (368 days) could also be causes for concern depending on the situation of radioactive release to the environment, as indicated in the Chernobyl accident [17].

\section{Materials and Methods}

\subsection{Projection of Absorbed Dose}

First, a situation of land contamination caused by fall-out ${ }^{137} \mathrm{C}$ deposited onto the ground is assumed. In this situation, external exposure to $\gamma$-rays from the ${ }^{137}$ Cs source in the ground surface is the main concern; internal exposure from radiocesium is supposed to be quite small as confirmed from the Fukushima Daiichi accident [3,4,18]; Kim et al. [18] 
reported that most of the committed effective doses from radiocesium $\left({ }^{137} \mathrm{Cs}\right.$ and $\left.{ }^{134} \mathrm{Cs}\right)$ determined based on whole-body-counter measurements were less than $0.1 \mathrm{mSv}$ for most of the examined residents ( 125 adults and 49 children) who lived near the Fukushima Daichi nuclear power station at the time of the accident.

Assuming that the whole-body absorbed dose of a resident in the initial year, $D(0)$, was well known through in situ measurements at the respective site, the chronological change of annual absorbed dose rate at time $=\mathrm{t}$ from radiocesium deposited onto the ground can be calculated as follows:

$$
D(t)=\left(D(0)-D_{B K G}\right) \cdot \exp \left(-\lambda_{137} \cdot t\right) \cdot f(t)
$$

where $D_{B K G}$ is the background dose rate at the site; $\lambda_{137}$ is the physical decay constant of ${ }^{137} \mathrm{Cs}$; and $f(t)$ is the attenuation function which is related to the cesium mobility in the surface soil layer. As the value of $D_{B K G}, 0.05 \mu \mathrm{Sv} \mathrm{h}{ }^{-1}\left(0.44 \mathrm{mSv} \mathrm{y}^{-1}\right)$ was employed from a previous study on the external dose assessment of the evacuee in Fukushima Prefecture [19]. It is empirically known that the observed dose-rate changes can be approximated well with $f(t)$ composed of a sum of two exponential functions, i.e., short-term and long-term decay components, as follows [2,20-23]:

$$
f(t)=\alpha \cdot \exp \left(-\frac{\ln 2}{T_{S}} \cdot t\right)+(1-\alpha) \cdot \exp \left(-\frac{\ln 2}{T_{L}} \cdot t\right)
$$

where $\alpha$ is a fraction of the short-term component; $T_{S}$ and $T_{L}$ are environmental halflives for short-term and long-term decay components, respectively, that characterize the disappearing rates from the respective local environment due to the natural removal phenomena and human activities for reusing the land. It is expected that the values of site-specific $T_{S}$ and $T_{L}$ could be derived from the on-site radiation monitoring data obtained for initial days by using the areal monitoring posts, monitoring vehicles, portable detectors, monitoring airplane, etc., as demonstrated at the Fukushima Daiichi accident [24].

In the present analyses, the environmental half-life of the long-term decay component $\left(T_{L}\right)$ was assumed to be 50 years in reference to the relevant work of Golikov et al. [20] in regard to the Chernobyl accident and also the assessment of United Nations Scientific Committee on the effects of atomic radiation (UNSCEAR) regarding the Fukushima Daiichi accident [2]. As to the fraction $(\alpha)$ and environmental half-life $\left(T_{S}\right)$ of the short-term component, large variations depending on the land-surface properties have been observed in the area affected by the Fukushima Daiichi accident $[3,22,23]$. Here, the 5th percentile, median and 95th percentile values of the "other than forest" undisturbed area in the evacuation zone were chosen from the paper of Kinase et al. [22] and subjectively formed three land categories, "Fast", "Middle", and "Slow", covering the wide range of the observed decaying patterns of ambient dose rate. The values adopted for $\alpha$ and $T_{S}$ corresponding to these three categories are shown in Table 2.

Table 2. The values of environmental half-life (Ts) and fraction $(\alpha)$ of the short-term decay component; they were adopted from the 5th percentile, median and 95th percentile values derived from the observations of ambient dose in Fukushima Prefecture [22].

\begin{tabular}{ccc}
\hline Land Category & $T_{S}[\mathbf{y}]$ & $\alpha$ [adu] \\
\hline Fast & 0.22 & 0.67 \\
Middle & 1.03 & 0.51 \\
Slow & 2.69 & 0.35 \\
\hline
\end{tabular}

\subsection{Projection of Cancer Risk}

In cancer risk projections, the author focused on female infants (0-year-old children) because this group is known to be the most radiation sensitive for whole-body external exposure in regard to the all-cancer risk. Figure 1 shows the plots of the lifetime attributable 
risk (LAR) of cancer mortality attributing to a single whole-body exposure of 0.1 Gy as a function of age at exposure [10]; here, the LAR values have been converted to the fraction [\%], while the original LAR values were given as the numbers of cases per 100,000 subjects. According to these data, the radiation-induced cancer risks of children is considered to be 2 to 3 times higher than those of adults; and female people are more susceptible to radiation than male people.

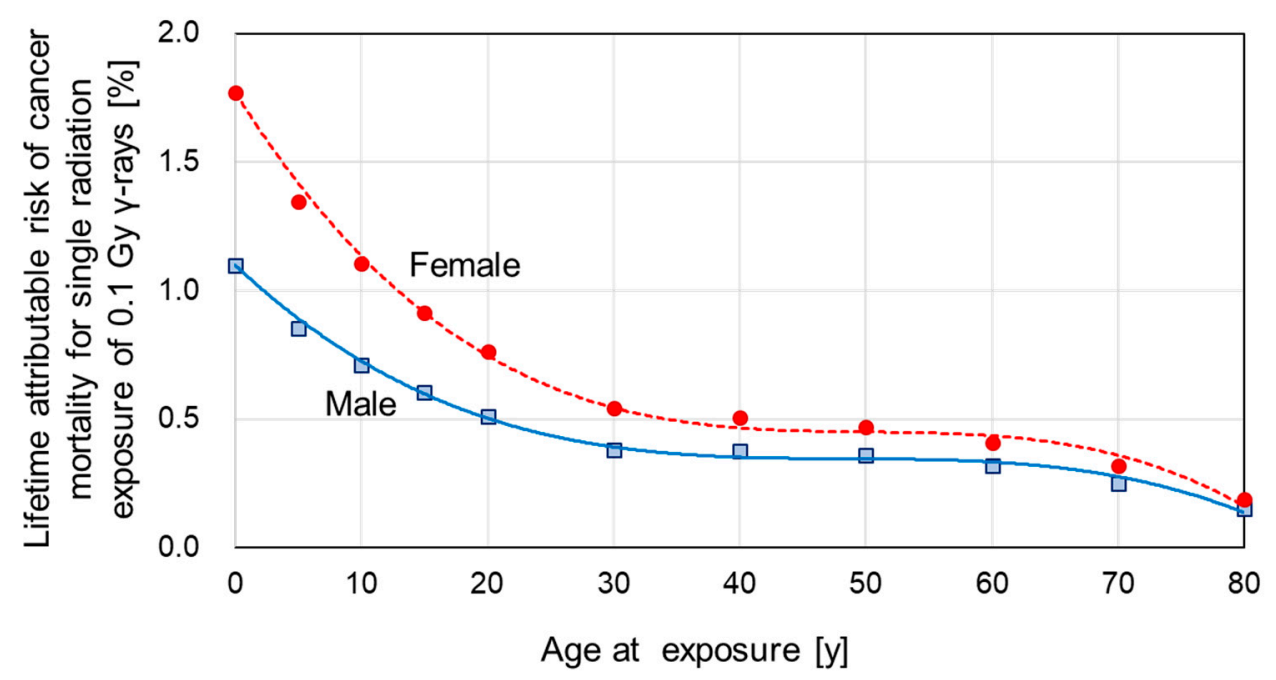

Figure 1. Lifetime attributable risk of radiation-induced cancer mortality as a function of age at exposure for male (solid line) and female people (dotted line) (after the BEIR VII report [10]).

With these facts, the author focused on female people as the critical group in assessment of life-long radiological risk and then predicted long-term cancer risks of female people for three time periods: 0 to 6 years (preschool), 0 to 18 years (up to high school graduation), and 0 to 80 years (lifetime). The integrated cancer-mortality risk for the period from 0 year to age $y, R(y)$, was calculated by integration of the products of the annual absorbed dose and corresponding LAR value for the respective period as follows:

$$
R(y)=\sum_{t=1}^{y}\{1-R(t-1)\} \cdot \frac{D(t)}{10^{2}} \cdot \operatorname{LAR}(t)
$$

where $R(0)$ is 0 ; and $D(t)$ is the annual absorbed dose rate at time $=\mathrm{t}\left[\mathrm{mGy} \mathrm{y}^{-1}\right]$. In general, $D(0)$ is to be determined from on-site monitoring data; and $D(1)$ and subsequent annual dose rates are estimated by the method described in Section 2.1. Calculations of the $R(y)$ values were performed with a manually made program of Visual Basic for Applications (VBA) of Microsoft Excel.

\section{Results and Discussions}

\subsection{Long-Term Cancer Risk}

Figure 2 shows the chronological changes of annual external dose rates of $\gamma$-rays from ${ }^{137} \mathrm{Cs}$ deposited onto the ground classified by the land categories (Fast, Middle, and Slow). Clear differences were seen in the decay patterns of the dose rates among three categories, which suggests that the land-surface properties could bring significant effects on the long-term radiation exposures of residents.

Using the predicted dose rate changes (Figure 2) and the data of age-dependent LAR (Figure 1), the author calculated integrated cancer-mortality risks of a female infant ( 0 years old) for her lifetime (up to 80 years old). The results are shown in Figure 3 as time plots of the integrated cancer risks for three land categories and also in Table 3 as the landdependent integrated risks for three periods from the birth: 6 years (preschool period), 18 years (up to high school), and 80 years (lifetime). It was found that the cancer-mortality 
risk of a female person could change by a factor of 2 depending on the land-surface properties; in other words, where to live.

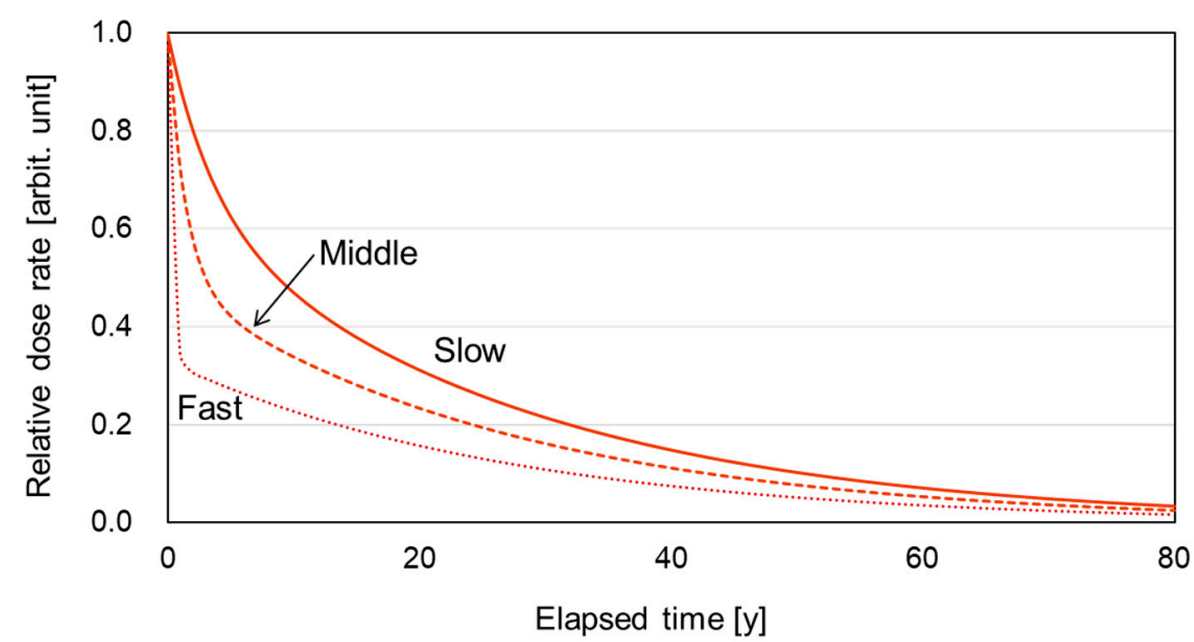

Figure 2. Predicted time change of the relative external dose rates from ${ }^{137} \mathrm{Cs}$ deposited onto the ground surfaces having different properties.

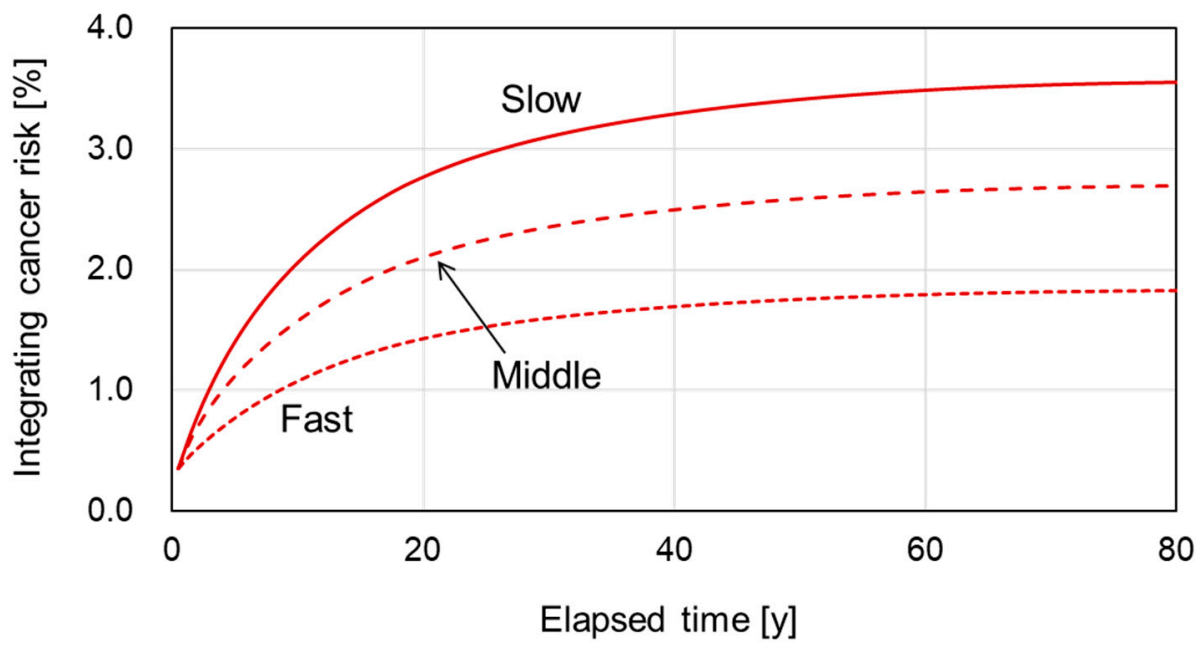

Figure 3. Predicted integrated cancer-mortality risk induced by $\gamma$-rays from ${ }^{137} \mathrm{Cs}$ deposited onto ground for a female infant ( 0 years old) at the initial dose rate of $20 \mathrm{mGy} \mathrm{y}^{-1}$.

Table 3. Integrated cancer risks of a female person for three periods at the areas having different land-surface properties with the initial dose rate of $20 \mathrm{mGy} \mathrm{y}^{-1}$.

\begin{tabular}{cccc}
\hline \multirow{2}{*}{$\begin{array}{c}\text { Land } \\
\text { Category }\end{array}$} & \multicolumn{3}{c}{ Integrated Cancer Risk [\%] } \\
\cline { 2 - 4 } & $\sim \mathbf{6}$ Years & $\sim \mathbf{1 8}$ Years & $\sim \mathbf{8 0}$ Years \\
\hline Fast & 0.88 & 1.40 & 1.83 \\
Middle & 1.28 & 2.05 & 2.69 \\
Slow & 1.64 & 2.70 & 3.56 \\
\hline
\end{tabular}

\subsection{Comparison with Nominal Risk}

Effective dose is a widely used quantity to evaluate the stochastic health effects of radiation exposure for the aim of radiological protection. This quantity is not defined for an individual person but for "Reference Person" which represents a nominal population having typical age and sex distributions. On the basis of this concept, nominal risk coefficients for estimating nominal risks from the effective dose are given for two groups: whole 
population (the public) and adults (workers) [7]. Thus, the risks estimated from effective doses should be the same for all members of an intended group regardless of the different physical and physiological properties. This nature was intentionally given for avoiding unnecessarily discriminatory actions, which means that this quantity is unsuitable for the purpose of assessing individual risks $[7,13]$.

If we employed the ICRP-recommended nominal risk coefficient $(5.5 \%$ for cancer mortality) [7] in calculation of the cancer risk for the whole population of residents that were assumed to live in the land having an average land-surface properties (i.e., the Middle category), the nominal risks following the initial dose rate of $20 \mathrm{mGy} \mathrm{y}^{-1}$ were calculated to be $0.45 \%$ for the preschool age ( 6 years), $0.86 \%$ for up to the high-school graduation, and $1.5 \%$ for lifetime ( 80 years) (Table 4 ). These values were much lower ( $35 \%$ to $57 \%$ ) than those calculated for a female person of the corresponding time period (Table 3 ).

Table 4. Nominal cancer risks estimated by using the nominal risk coefficients of ICRP [6] and the ratios of those nominal risks to the specific risks of a female person calculated in this study (Table 3) for three areas having different land-surface properties.

\begin{tabular}{ccccccc}
\hline \multirow{2}{*}{$\begin{array}{c}\text { Land } \\
\text { Category }\end{array}$} & \multicolumn{3}{c}{ Nominal Cancer Risk [\%] } & \multicolumn{3}{c}{ Ratio (Nominal/Specific) } \\
\cline { 2 - 7 } & $\sim \mathbf{6}$ Years & $\sim \mathbf{1 8}$ Years & $\sim \mathbf{8 0}$ Years & $\sim \mathbf{6}$ Years & $\sim \mathbf{1 8}$ Years & $\sim \mathbf{8 0}$ Years \\
\hline Fast & 0.305 & 0.582 & 1.03 & 0.347 & 0.417 & 0.562 \\
Middle & 0.449 & 0.861 & 1.53 & 0.353 & 0.421 & 0.566 \\
Slow & 0.584 & 1.15 & 2.03 & 0.357 & 0.426 & 0.571 \\
\hline
\end{tabular}

The findings above imply that the currently common approach using effective dose would lead to an inappropriate judgement in the process of decision making regarding protective actions such as evacuation, relocation and decontamination following the concept for optimization in radiological protection, i.e., "As Low As Reasonably Achievable (ALARA)" [7,9]. It is expected that the alternate risk-based approach presented in this study would be useful for more appropriate judgement in optimization based on the integrated risk of all hazardous materials including heavy ions and toxic organic compounds in the living environment and the different sensitivities of the respective people to those materials.

It should be noted that difficulties still remain in the application of the presented approach to the decision making regarding protective actions. It is envisaged that many of the residents would prefer to behave as a community and they would not consider the difference in individual health status as an important matter. Moreover, the fear of radiation exposure would force them to just stay distant from the affected area, while it would not necessarily reduce the total health risk because some other effects, including psychological stress, could bring about more significant impacts on physiological status, as highlighted in the Fukushima Daiichi accident $[5,6]$. More efforts are needed for practical application of the presented approach based on the firm concept of minimizing the overall risk with consideration of social, economic, and psychological factors as well as the radiological consequences.

\section{Conclusions}

When a severe nuclear accident occurs, it is crucial to make prompt decisions on the measures for protecting people from excessive exposure to the radioactive sources in the living environment and other possible hazards. For contributing to this important decision making, the author has presented an approach for site-specific cancer risk projections of the most radiosensitive group following large-scale land contamination caused by radiocesium deposition. The obtained results indicated that accurate site-specific information on the behavioral characteristics of the radionuclides in the ground surface of the land is critically important for precise prediction of future consequences on the health of affected people.

The findings of this study indicate that we need to know, in advance, the physicochemical properties of the living environment of residents for maximizing our overall well-being 
through the best possible optimization of various risks and benefits for an unexpected event accompanied by large-scale environmental contamination. While recognizing that it is not an easy task, the author believes that such site-specific assessment of individual risks would enable the authority to make more appropriate decisions on protective actions, such as evacuation, relocation and decontamination, for averting excessive exposures to all hazards, including social, economic, and psychological impacts.

Funding: This research received no external funding.

Institutional Review Board Statement: Not applicable.

Informed Consent Statement: Not applicable.

Data Availability Statement: Not applicable.

Acknowledgments: This work was partially supported by the Program of the Network-Type Joint Usage/Research Center for Radiation Disaster Medical Science of Hiroshima University.

Conflicts of Interest: The author declares no conflict of interest.

\section{References}

1. Fukushima Prefectural Government. Fukushima Revitalization Station. Available online: http://www.pref.fukushima.lg.jp/site/ portal/list271.html (accessed on 30 March 2021). (In Japanese)

2. United Nations Scientific Committee on the Effects of Atomic Radiation (UNSCEAR). UNSCEAR 2013 Report to the General Assembly with Scientific Annexes, Annex A: Levels and Effects of Radiation Exposure due to the Nuclear Accident after the 2011 Great East-Japan Earthquake and Tsunami; United Nations: New York, NY, USA, 2014.

3. International Atomic Energy Agency (IAEA). The Fukushima Daiichi Accident; IAEA: Vienna, Austria, 2015.

4. United Nations Scientific Committee on the Effects of Atomic Radiation (UNSCEAR). UNSCEAR 2020 Report to the General Assembly with Scientific Annexes, Annex B (Advance Copy): Levels and Effects of Radiation Exposure due to the Accident at the Fukushima Daiichi Nuclear Power Station: Implications of Information Published since the UNSCEAR 2013 Report; United Nations: New York, NY, USA, 2021.

5. Hasegawa, A.; Ohira, T.; Maeda, M.; Yasumura, S.; Tanigawa, K. Emergency Responses and Health Consequences after the Fukushima Accident; Evacuation and Relocation. Clin. Oncol. 2016, 28, 237-244. [CrossRef] [PubMed]

6. Maeda, M.; Oe, M. Mental health consequences and social issues after the Fukushima Disaster. Asia Pacif. J. Public Health 2017, 19, 365-465. [CrossRef] [PubMed]

7. International Commission on Radiological Protection (ICRP). 2007 Recommendations of the International Commission on Radiological Protection; Publication 103; ICRP: Ottawa, ON, Canada, 2007.

8. International Commission on Radiological Protection (ICRP). Radiological Protection of People and the Environment in the Event of a Large Nuclear Accident; Publication 146; SAGE: London, UK, 2020.

9. International Commission on Radiological Protection (ICRP). 1990 Recommendations of the International Commission on Radiological Protection; Publication 60; Pergammon Press: Oxford, UK, 1991.

10. U.S. National Research Council. Health Risks from Exposure to Low Levels of Ionizing Radiation, BEIR VII Phase 2; National Academies Press: Washington, DC, USA, 2006.

11. United Nations Scientific Committee on the Effects of Atomic Radiation (UNSCEAR). UNSCEAR 2006 Report to the General Assembly with Scientific Annexes, Annex A: Epidemiological Studies of Radiation and Cancer; United Nations: New York, NY, USA, 2008.

12. United Nations Scientific Committee on the Effects of Atomic Radiation (UNSCEAR). UNSCEAR 2013 Report to the General Assembly with Scientific Annexes, Annex B: Effects of Radiation Exposure of Children; United Nations: New York, NY, USA, 2013.

13. International Commission on Radiological Protection (ICRP). Use of Dose Quantities in Radiological Protection; Publication 147; SAGE: London, UK, 2021.

14. Howard, B.J.; Fesenko, S.; Balonov, M.; Pröhl, G.; Nakayama, S. A comparison of remediation after the Chernobyl and Fukushima Daiichi accidents. Radiat. Prot. Dosim. 2017, 173, 170-176.

15. Shizuma, M.; Nursal, W.K.; Sakura, Y. Long-term monitoring of radiocesium concentration in sediments and river water along five rivers in Minami-soma City during 2012-2016 following the Fukushima Daiichi nuclear power plant accident. Appl. Sci. 2018, 8, 1319. [CrossRef]

16. Wai, K.-M.; Krstic, D.; Nikezic, D.; Lin, T.-H.; Yu, P.K.N. External Cesium-137 doses to humans from soil influenced by the Fukushima and Chernobyl nuclear power plants accidents: A comparative study. Sci. Rep. 2020, 10, 7902. [CrossRef] [PubMed]

17. United Nations Scientific Committee on the Effects of Atomic Radiation (UNSCEAR). UNSCEAR 2008 Report to the General Assembly with Scientific Annexes, Annex D: Health Effects due to Radiation from the Chernobyl Accident; United Nations: New York, NY, USA, 2011. 
18. Kim, E.; Kurihara, O.; Kunishima, N.; Nakano, T.; Tani, K.; Hachiya, M.; Momose, T.; Ishikawa, T.; Tokonami, S.; Hosoda, M.; et al. Early intake of radiocesium by residents living near the TEPCO Fukushima Dai-Ichi Nuclear Power Plant after the accident. Part 1: Internal doses based on whole-body measurements by NIRS. Health Phys. 2016, 111, 451-464. [CrossRef] [PubMed]

19. Akahane, K.; Yonai, S.; Fukuda, S.; Miyahara, N.; Yasuda, H.; Iwaoka, K.; Matsumoto, M.; Fukumura, A.; Akashi, M. NIRS external dose estimation system for Fukushima residents after the Fukushima Daiichi NPP accident. Sci. Rep. 2013, 3, 1670. [CrossRef] [PubMed]

20. Golikov, V.Y.; Balonov, M.I.; Jacob, P. External exposure of the population living in areas of Russia contaminated due to the Chernobyl accident. Radiat. Environ. Biophys. 2002, 41, 185-193. [CrossRef] [PubMed]

21. Tsubokura, M.; Murakami, M.; Nomura, S.; Morita, T.; Nishikawa, Y.; Leppold, C.; Kato, S.; Kami, M. Individual external doses below the lowest reference level of $1 \mathrm{mSv}$ per year five years after the 2011 Fukushima nuclear accident among all children in Soma City, Fukushima: A retrospective observational study. PLoS ONE 2017, 12, e0172305. [CrossRef] [PubMed]

22. Kinase, S.; Takahashi, T.; Saito, K. Long-term predictions of ambient dose equivalent rates after the Fukushima Daiichi nuclear power plant accident. J. Nucl. Sci. Technol. 2017, 54, 1345-1354. [CrossRef]

23. International Atomic Energy Agency (IAEA). Environmental Transfer of Radionuclides in Japan following the Accident at the Fukushima Daiichi Nuclear Power Plant; IAEA-TECDOC-1927; IAEA: Vienna, Austria, 2020.

24. Nuclear Regulation Authority (NRA). Monitoring Information of Environmental Radioactivity Level. Available online: http: / / radioactivity.nsr.go.jp/ja/list/564/list-1.html (accessed on 10 May 2021). (In Japanese) 